\title{
Jourmat Vascular
}

\section{4-5 June, 2016}

Phosphorylation and G-Protein Mediated Signaling Networks Gordon Research Seminar

Emerging Advances in Signaling Downstream of GPCRs and Kinases from Basic Mechanisms to Human Disease

University of New England, Biddeford, Maine, USA

http://www.grc.org/programs.aspx?id=15402

4-5 June, 2016

Fibroblast Growth Factors in Development \& Disease

Gordon Research Seminar

FGF Signalling: From Molecular Understanding to Therapeutic Targeting

The Chinese University of Hong Kong, Hong Kong, China

https://www.grc.org/programs.aspx?id=15283

5-10 June, 2016

Fibroblast Growth Factors in Development \& Disease

Gordon Research Conference

FGF Signalling: From Molecular Understanding to Therapeutic Targeting

The Chinese University of Hong Kong, Hong Kong, China

http://www.grc.org/programs.aspx?id=13592

\section{5-10 June, 2016}

FASEB Science Research Conference

Cell Signaling in Cancer: from Mechanisms to Therapy

Base Village Conference Center, Snowmass Village, Colo., USA

http://www.faseb.org/SRC-Microsite/CellSig/Home.aspx

12-17 June, 2016

FASEB Science Research Conference

Ubiquitin \& Cellular Regulation

Mountain Mall, Mammoth Room, Big Sky, Mont., USA

http://www.faseb.org/SRC-Microsite/Ubiq/Home.aspx

12-17 June, 2016

FASEB Science Research Conference

Calcium and Cell Function

Lisbon Marriott Hotel, Lisbon, Portugal

http://www.faseb.org/SRC-Microsite/Calcium/Home.aspx

3-8 July, 2016

Cell Death

Gordon Research Conference

New Concepts in Cell Death Research: From Basic Mechanisms to Clinical Opportunities

PGA Catalunya Business and Convention Centre, Girona, Spain http://www.grc.org/programs.aspx?id=12477
17-22 July, 2016

FASEB Science Research Conference

Protein Kinase Signaling Network Regulation

Base Village Conference Center, Snowmass Village, Colo., USA

http://www.faseb.org/SRC-Microsite/ProKinase/Home.aspx

21-25 July, 2016

$12^{\text {th }}$ International Congress of Cell Biology

Exploring Cellular Structure and Function

Prague Congress Centre, Prague, Czech Republic

http://www.iccb2016.org/topics.htm

29-31 July, 2016

Physiology 2016

Joint Meeting of the American Physiological Society and

The Physiological Society

Convention Centre Dublin, Ireland

http://www.physiology2016.org/

30 October-3 November, 2016

International Vascular Biology Meeting 2016

Sheraton Boston Hotel, Boston, Mass., USA

http://www.navbo.org/events/ivbm-2016

6-9 November, 2016

$12^{\text {th }}$ International Symposium on Mechanisms of Vasodilatation Mayo Clinic, Rochester, Minn., USA

http://movd2016.org/

June, 2017

European Society for Microcirculation, $29^{\text {th }}$ Meeting

Switzerland

http://www3.szote.u-szeged.hu/esm/

5-6 August, 2017

Angiogenesis

Gordon Research Seminar

Salve Regina University, Newport, R.I., USA

http://www.grc.org/programs.aspx?id=14618

6-11 August, 2017

Angiogenesis

Gordon Research Conference

Salve Regina University, Newport, R.I., USA

http://www.grc.org/programs.aspx?id=12508

1-5 September, 2017

International Symposium for Resistance Arteries

Manchester, UK 